\title{
Proposta de Metodologia para Melhoria do Desempenho do Sistema de Gestão no Novo Sindicalismo Brasileiro Após a Reforma Trabalhista
}

\author{
${ }^{1}$ Rousilene C. Carvalho Melo (UNIVERSIDADE FEDERAL FLUMINENSE) \\ rousilenemelo@gmail.com \\ ${ }^{2}$ Stella Regina Reis da Costa (UNIVERSIDADE FEDERAL FLUMINENSE) \\ stellare@ig.com.br
}

\section{Resumo}

Até 2017 uma grande parte dos sindicatos eram mantidos por uma taxa compulsória intitulada como taxa sindical. Com o advento da nova Reforma Trabalhista, essa contribuição que era compulsória foi extinta, deixando grande parte destes sindicatos à deriva e perto de sua extinção (principalmente os sindicatos laborais, embora o objeto desta pesquisa ser os sindicatos patronais) vários sindicatos entraram em colapso financeiro. $\mathrm{O}$ sistema sindical brasileiro está se reinventando para continuar com sua existência. Neste artigo foi levantando o cenário atual ao qual os sindicatos patronais na área de terceirização de mão de obra de asseio, conservação, segurança privada e de transporte de valores estão vivenciando, a pesquisa foi baseada em revisões de literatura com os temas qualidade, gestão, modelos de gestão, sindicato e sindicalismo para sustentar o estudo do tema. O presente artigo tem como objetivo principal apresentar um respaldo que permite a liderança destas entidades sindicais obter a percepção de gestão da qualidade em suas entidades sindicais.

Palavras-Chaves: Modelo de Gestão, Sindicalismo, Qualidade, Sindicato, Terceirização.

Until 2017 a large part of the unions were maintained by a compulsory fee entitled as union fee. With the advent of the new Labor Reform, this mandatory contribution was extinguished, leaving a large part of these unions adrift and close to their extinction (mainly the labor unions, although the object of the research was the employers' unions), several unions collapsed. financial. The Brazilian union system is reinventing itself to continue its existence. In this article, the current scenario that employers' unions in the area of outsourcing clean labor, conservation, private security and cash transportation are experiencing is raised, the research was based on literature reviews with the themes quality, management, management, union and unionism models to support the study of the theme. The main objective of this 
article is to provide support that allows the leadership of these union entities to obtain the perception of quality management in their union entities.

Keywords: Management Model, Unionism, Quality, Union, Outsourcing.

\section{Introduçãa}

Oliveira (2009) em seu objeto de pesquisa, relata que foi no ano de 1937 através de Getúlio Dornelles Vargas, Presidente da República Federativa do Brasil na época, que foi oficializado o início do sindicalismo brasileiro, concomitante com o direito do trabalho, através do Decreto $N^{\circ} 19.770$ de 1931, em março de 1937. Entende-se que foi com o advento da CLT, mais precisamente em 01 de maio de 1943, que houve a promulgação da inclusão do imposto sindical, ou seja, foi imposta uma contribuição compulsória às categorias laborais e patronais, independente destes empregados ou empregadores serem sindicalizados, ou não.

Quando estudada a origem do direito coletivo do trabalho de acordo o autor Carvalho (2011), nota-se que em meados dos anos 20 no Brasil, o Estado interveio no movimento sindical com a implantação do princípio da unicidade sindical, que importa em poder haver somente um sindicato representando certa categoria numa mesma base territorial, impossibilitando a coexistência de vários sindicatos representando a mesma categoria numa mesma base territorial. Essa definição de "Unicidade Sindical" é o antônimo de "pluralidade sindical", a qual se define como sendo o modelo em que vários sindicatos podem representar uma mesma categoria numa mesma base territorial. A unicidade sindical foi instituída pelo governo de Getúlio Vargas, quando da criação do Ministério do Trabalho (CARVALHO, 2011).

Até 2017, os sindicatos possuíam uma arrecadação concreta, tanto laboral quanto patronal e a certeza da arrecadação era certa, havia inadimplência, mas tinham arrecadação garantida. Com a Reforma Trabalhista de 2017, levada a efeito através da LEI No 13.467, DE 13 DE JULHO DE 2017 as empresas ficaram desobrigadas de realizar o recolhimento, tendo a opção de fazê-lo, se assim acharem necessário. Já foi através da MEDIDA PROVISÓRIA Nº 873, DE $1^{\circ}$ DE MARÇO DE 2019, publicada no Diário Oficial da União em 01/03/2019 Edição Extra, que alterou a CLT, inclusive em pontos já modificados pela denominada Reforma Trabalhista, nos quais apresentou determinações que deixaram ainda mais difícil a arrecadação de taxas denominadas compulsórias em favor dos sindicatos patronais e laborais, proibindo constar em Convenção Coletiva ou Acordo Coletivo, cláusula que obrigue o desconto no salário do empregado sem a sua autorização "prévia, expressa, voluntária e 
individual", sendo nula regra ou cláusula normativa que fixar a compulsoriedade ou a obrigatoriedade de recolhimento a empregados ou empregadores, ainda que referendada por negociação coletiva, assembleia geral ou outro meio previsto no estatuto da entidade sindical.

Mediante a este cenário advindo da Reforma Trabalhista, percebe-se a necessidade da reestruturação das organizações sindicais ao novo sindicalismo brasileiro. Os sindicatos necessitam serem autossustentáveis para que se sobrevivam, mormente obter recursos financeiros, obrigando-os a "ser" o que eles deveriam "ser": representativos, fornecedores e defensores das suas categorias. O ponto de partida para essa mudança, pode estar na implantação de um Modelo Gestão com foco na organização sindical.

O presente artigo tem como objetivo principal citar alguns pontos da trajetória do sindicalismo brasileiro, culminado na Reforma Trabalhista de 2017 e apresentar um respaldo que permite a liderança destas entidades sindicais obter a percepção de gestão da qualidade.

\section{Fundamentação Teórica}

Feigenbaum (1994) define o termo qualidade como sendo a entrega de determinado produto ou serviço, possuindo características pontuais que atendem e satisfaz as necessidades e expectativas dos clientes. É o ato de resolver os problemas e solucionar suas causas e efeitos ao longo da vida útil do produto ou serviço. Envolve desde o planejamento/ desenvolvimento e seus responsáveis, com interação entre funcionários independente do cargo que ocupam dentro das organizações, até a linha de fabricação. Envolve, também, os próprios clientes e os fornecedores que, com essa ação, buscam o aperfeiçoamento das atividades e técnicas desenvolvidas para alcançar o mais próximo da perfeição aos olhos dos clientes (MAXIMIANO, 2011).

Quanto ao conceito de Gestão, este está relacionado a um conjunto de atividades utilizadas para controlar, planejar, medir e melhorar as atividades gerenciais e administrativas nas organizações. Já um modelo de gestão é a maneira de descrever a forma de gerir este conjunto de atividades, possibilitando dimensionar o impacto destes elementos dentro de uma organização, (PAGLIUSO, 2010).

Um modelo de Gestão pela Qualidade tem por objetivo auxiliar as atividades dentro de uma organização, possibilitando aplicar métodos para controle em todas as esferas, buscando eliminar falhas e obter um resultado financeiro satisfatório alinhado com uma boa qualidade na prestação de seus serviços e produtos (MOMBACHI, PEREIRA E COSTA, 2011). 


\section{Metodologia}

A natureza desta pesquisa é a de Desenvolvimento Experimental. Utilizou-se a pesquisa exploratória e o método escolhido foi o qualitativo. A modalidade de pesquisa utilizada foi de Estudo de Caso múltiplos, onde os sindicatos SEAC e SINDESP-GO serviram como sindicatos pilotos para a realização das entrevistas e posteriormente, implantação de uma metodologia para melhoria do desempenho do sistema de gestão. Foram realizadas entrevistas com os presidentes dos sindicatos da área de terceirização de mão de obra de asseio, conservação, segurança privada e transporte de valores, com intuito de obter um diagnóstico da gestão desenvolvida nestas entidades.

O universo de possíveis respondentes era de 58 indivíduos, sendo 28 presidentes de sindicatos da área de terceirização de mão de obra de asseio e conservação, 27 presidentes de sindicatos da área de segurança privada e transporte de valores, 02 presidentes de federações e 01 expresidente. Do universo total da população de 58 indivíduos foi entrevistada uma amostra de 40 respondentes.

Utilizou-se a entrevista semiestruturada, as perguntas foram preparadas de forma antecipada, e as questões foram padronizadas, aplicou-se as mesmas perguntas a todos os entrevistados de acordo com seu grupo, sendo direcionadas para os Gestores Executivos ou para os Presidentes das entidades sindicais.

Foram elaboradas e aplicadas 10 perguntas para realização das entrevistas, as quais foram iniciadas com os Presidentes e o Executivo dos Sindicatos pilotos, após deu-se continuidade com os demais representantes sindicais, dos sindicatos que estão sitiados nas regiões norte, nordeste, sul, sudeste e centro-oeste do Brasil. Realizou-se uma indução analítica dos dados, analisando as entrevistas de forma individual resultando em um padrão comum.

A codificação dos dados coletados não possui uma regra especifica. O autor Grey (2012) sugere a utilização de alguns princípios para realização desta codificação, e cita que, é a partir da transcrição dos dados, desmembramento, análise de forma macro, alinhamento e junção é que se pode ter acesso a um novo conceito daquilo que foi estudado e objetivado na pesquisa.

\section{Resultados e discussão}

As entrevistas foram iniciadas com os Presidentes dos Sindicatos pilotos. Após deu-se continuidade com os demais representantes sindicais, dos sindicatos que estão sitiados nas 
regiões norte, nordeste, sul, sudeste e centro-oeste do Brasil. Realizou-se uma indução analítica dos dados, analisando as entrevistas de forma individual, no que resultando em um padrão comum.

a) Pergunta 1: Sua Entidade estava preparada para extinção da taxa sindical?

Figura 1 - Resultados da Pergunta 1

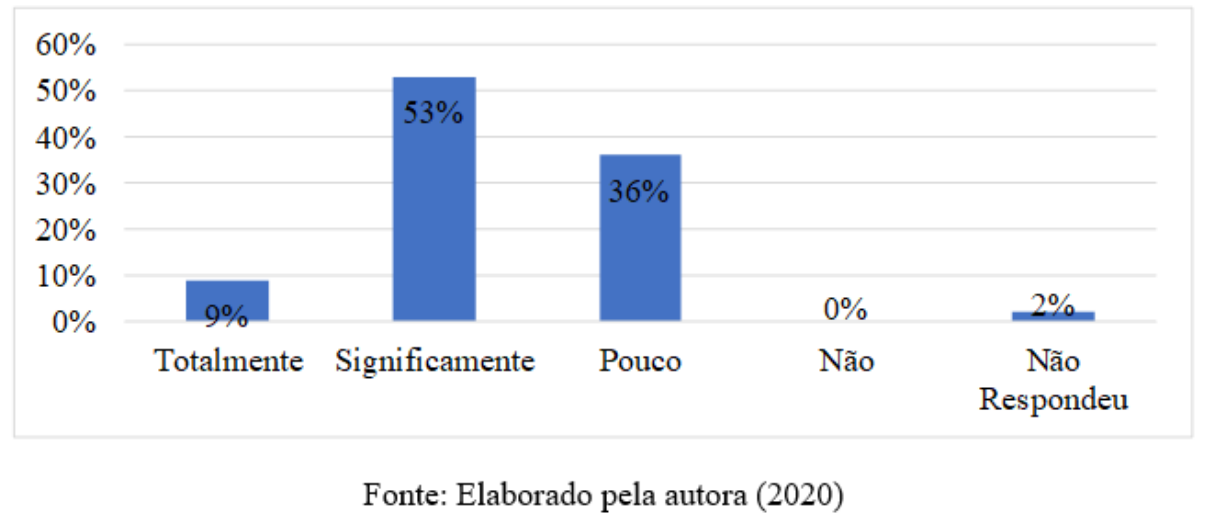

De acordo com os dados coletados, a maioria estava preparada para extinção da contribuição sindical. A Medida Provisória 873 de 11/0612019, remete a exclusão da obrigatoriedade de recolhimento da taxa sindical. Já havia rumores da promulgação dessa Lei antes da mesma ser sancionada. Alguns sindicatos se anteciparam e implementaram ações de reparação da receita, outros esperaram acontecer. Vale salientar que nestas categorias a liderança dos sindicatos já detinham o conhecimento e nenhuma entidade sindical foi desprovida da informação.

b) Pergunta 2: Qual o percentual de arrecadação a Contribuição Sindical representava em sua arrecadação anual?

Figura 2 - Resultados da Pergunta 2

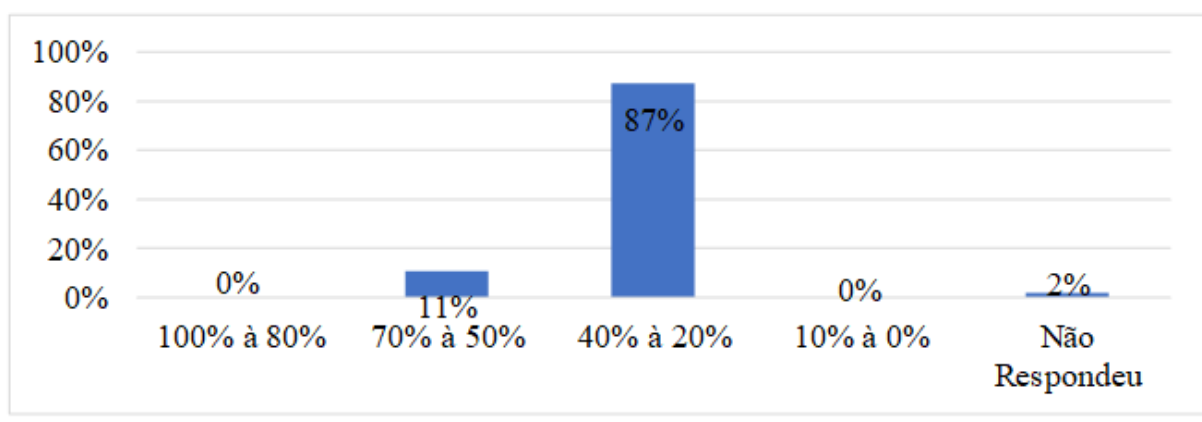

Fonte: Elaborado pela autora (2020)

Nota-se que $87 \%$ dos presidentes responderam estarem na mesma margem de arrecadação da contribuição sindical. Respaldados anteriormente pela determinação na Consolidação das Leis Trabalhistas pelos artigos 578 e 587, e posteriormente através da Constituição Federal de 1988, os sindicatos constituídos legalmente, detinham do direito de obtenção de taxas 
compulsórias para se estruturarem financeiramente. Uma dessas taxas era a contribuição sindical. Nota-se que todos os sindicatos pesquisados se utilizavam desse benefício, embora com diferentes índices de arrecadação e representação em valor $\mathrm{R}$ em suas finanças. Nas categorias de asseio, conservação e de segurança privada, foi detectado que a arrecadação dessa antiga taxa compulsória representava entre $50 \%$ e $70 \%$ da arrecadação anual nos sindicatos, resultando um grande impacto na estrutura financeira.

c) Pergunta 3: Como a Liderança exerce a representatividade perante seus representados?

Figura 3 - Resultados da Pergunta 3

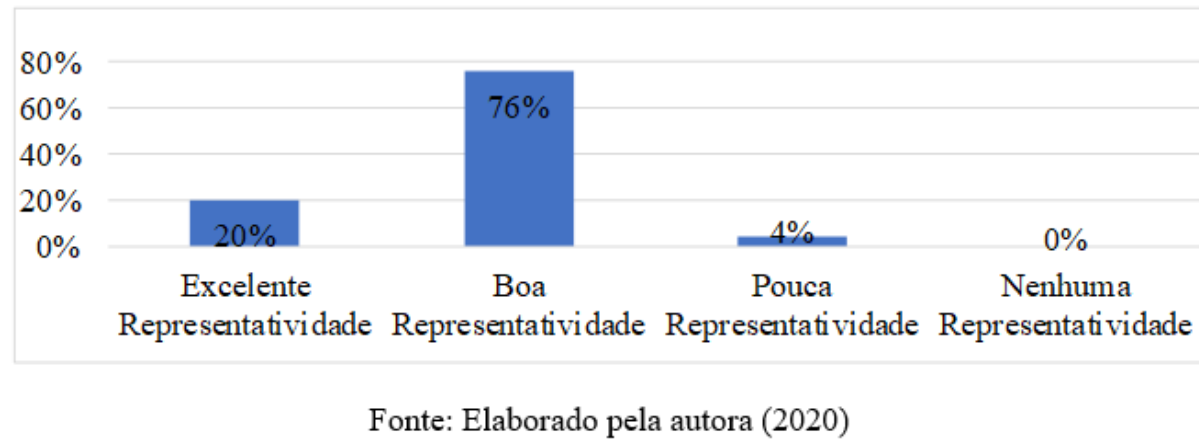

De acordo com o gráfico, $76 \%$ dos respondentes informaram possuírem uma boa representatividade. O processo de representatividade foi descrito, embora com algumas falhas. Amauri (2015) argumenta que representatividade é o ato de exercer a representação de forma eficaz, ou seja, em fazer as coisas certas. Mediante tal afirmativa pode-se constatar que as entidades sindicais pesquisadas estão promovendo ações de representatividade. Durante as entrevistas foram descritas algumas formas de como a liderança exerce a representatividade, como por exemplo, ações que lhes proporcionem a racionalização dos tributos, liberdade individual e coletiva na relação de emprego, combate à informalidade, luta pela longevidade das empresas e parceria para $e$-commerce.

d) Pergunta 4: Sua entidade assegura os recursos financeiros necessários para atender às necessidades operacionais e manter o fluxo financeiro equilibrado? 
Figura 4 - Resultados da Pergunta 4

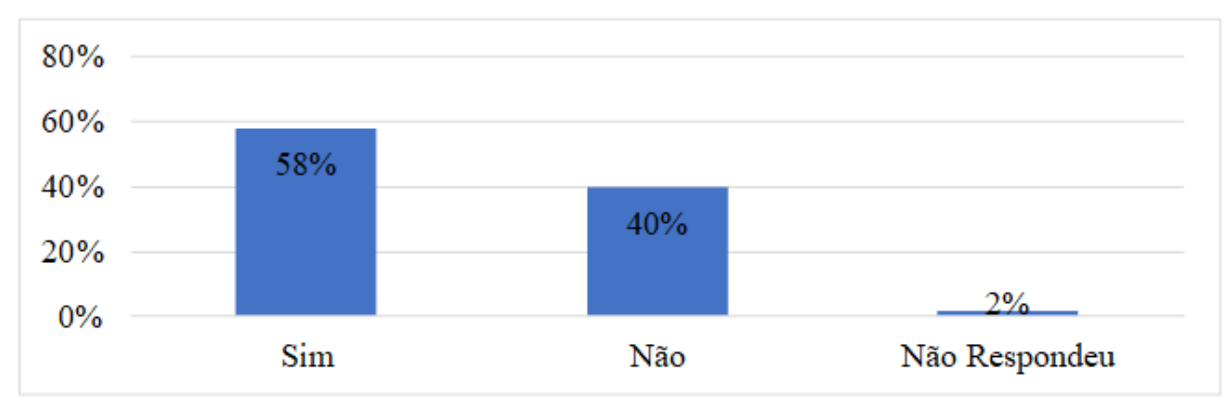

Fonte: Elaborado pela autora (2020)

Percebe-se que a maioria dos respondentes informou que sim, sua entidade assegura os recursos financeiros necessários para atender às necessidades operacionais e manter o fluxo financeiro equilibrado. Todos os entrevistados informaram que possuem processo de controle financeiro, cada um de acordo com sua particularidade, mas atendendo as prerrogativas estipuladas por lei para o controle contábil.

O autor Defeo (2015) ressalta a necessidade de as organizações possuírem controles, e controles de qualidade, os quais venham a atender as necessidades dos clientes, internos e externos. Durante a entrevista ao descreverem os processos financeiros de suas entidades, alguns deram exemplos de controles financeiros utilizados no gerenciamento dos sindicatos, como demonstrativos financeiros de controles diários, semanais, mensais, anuais.

e) Pergunta 5: Você tem conhecimento de quem são seus clientes?

Figura 5 - Resultados da Pergunta 5

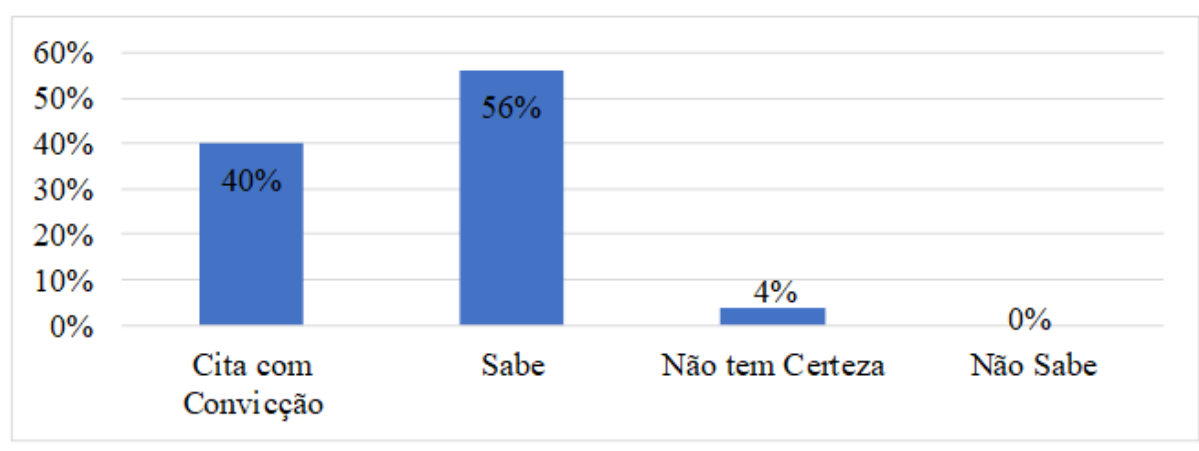

Fonte: Elaborado pela autora (2020)

A maioria dos respondentes relatou conhecer seus clientes, e ou, potenciais clientes, embora com ênfases diferentes. Contudo, embasado pela afirmação do autor Pagliuso (2010) que instrui que as organizações devem conhecer seus "clientes", pois estes clientes são quem garantem seus sustentos financeiros, os sindicatos pesquisados estão no caminho correto. Foi traçado um paralelo entre a afirmação do autor Pagliuso e as ações realizadas pelas entidades 
que comprovem a sinergia entre sindicato x cliente. Exemplo disso é possuírem cadastros das empresas atualizados de acordo com a junta comercial de cada Estado, possuir canais de comunicação de fácil acesso, monitorar as necessidades dos clientes através de aplicação de pesquisa, reuniões, comissões, dentre outras ações.

Um ponto a ser observado é que as entidades tem dificuldade de saber onde estão e a forma de abordar esses clientes. Alguns sindicatos, como por exemplo o SEAC e SINDESP-GO, possuem ações de localizar esses clientes através de parcerias com os sindicatos laborais e juntas comerciais. Também, realizam reuniões para levantamento de necessidades pontuais, dentre outras.

f) Pergunta 6: A forma como você vê seu cliente hoje é diferente da forma como ele era visto antes da Reforma Trabalhista?

Figura 6 - Resultados da Pergunta 6

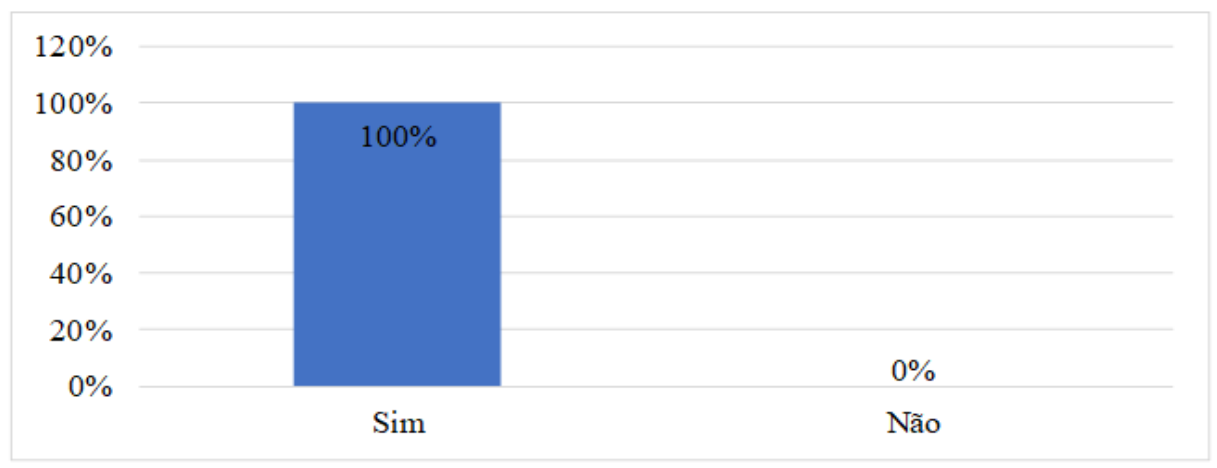

Fonte: Elaborado pela autora (2020)

Todos respondentes concordam que sim. Após a Reforma Trabalhista a forma como eles veem e, se relacionam com seus clientes mudou. Mediante esse resultado, que condiz com a sugestão de Pagliuso (2010) na afirmação que dependerá da qualidade dos produtos e serviços oferecidos a seus clientes para permanência dos mesmos em seu quadro de associado, possibilitando o sustento financeiro da entidade, e não mais oriundos da obrigatoriedade de arrecadações compulsórias, trazida pela legislação. Respaldado também por (CUNHA, 2018) que afirma que os sindicatos devem agregar serviços de forma satisfatória, visto que todo o cenário sindical se modificou após a Reforma Trabalhista, e a forma como os clientes dos sindicatos eram vistos e tratados, mudou.

g) Pergunta 7: Sua Entidade fideliza seus clientes? Se sim, como? 
Figura 7 - Resultados da Pergunta 7

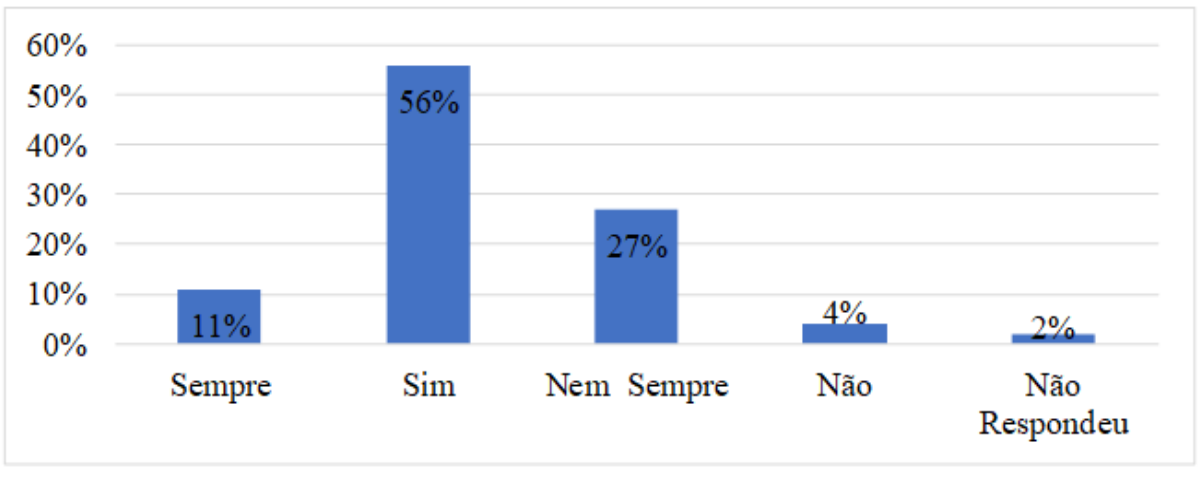

Fonte: Elaborado pela autora (2020)

De acordo com o gráfico a maioria dos respondentes informou que fidelizam seus clientes. Defeo (2015) cita que a satisfação e a fidelidade dos clientes só são alcançadas quando o conjunto de características pré-estabelecidas por eles são entregues sem falhas no seu processo e de forma eficiente e eficaz, sendo que ambas características afetam o desempenho financeiro. Essa afirmação vai ao encontro das respostas dos pesquisados, embora possa-se observar que nas resposta da pergunta 5 e nesta, alguns dos respondentes afirmaram que em suas entidades houve várias empresas que se desfiliaram, houve perda de arrecadação, e todos esses foram pontuais ao afirmarem que suas entidades tiveram que se reinventar para poderem continuar "de portas aberta". Com esse paralelo pode-se afirmar que a definição de fidelização de cliente não está clara para alguns dos entrevistados, visto que houve perda de cliente e não fidelização. $\mathrm{O}$ fato de o cliente ter sido compulsório até a reforma obrigará a estes sindicatos reverem as formas de captação e fidelização dos mesmos, uma novidade para as suas gestões.

As respostas desta questão não condizem com o cenário. A manutenção da associação das empresas é uma das formas de medida fidelização do cliente, pois só fica associada à entidade aquelas empresas que recebem um produto ou serviço que atendam à suas necessidades e expectativas. Se houve desfiliações acentuadas e diminuição das receitas é porque poucos sindicatos conseguem fidelizar seus clientes. A grande maioria, está com dificuldades financeiras, conforme externado por alguns destes sindicatos, a ponto de não terem recursos financeiros para custear as despesas fixas como pagamento de saneamento básico, energia, aluguel, dentre outras despesas.

Um dos exemplos de fidelização explanado por alguns dos respondentes foram: Realizarem atendimentos tendo o associado como o centro de tudo com foco em suas necessidades, 02 sindicatos não cobram nada de seus associados para que os mesmos possam usarem suas 
instalações (auditório, salão de festas e salas de reuniões), oferecem às empresas treinamentos e aperfeiçoamento da mão de obra administrativa e operacional de seus funcionários.

h) Pergunta 8: Sua Entidade possui indicadores?

Figura 8 - Resultados da Pergunta 8

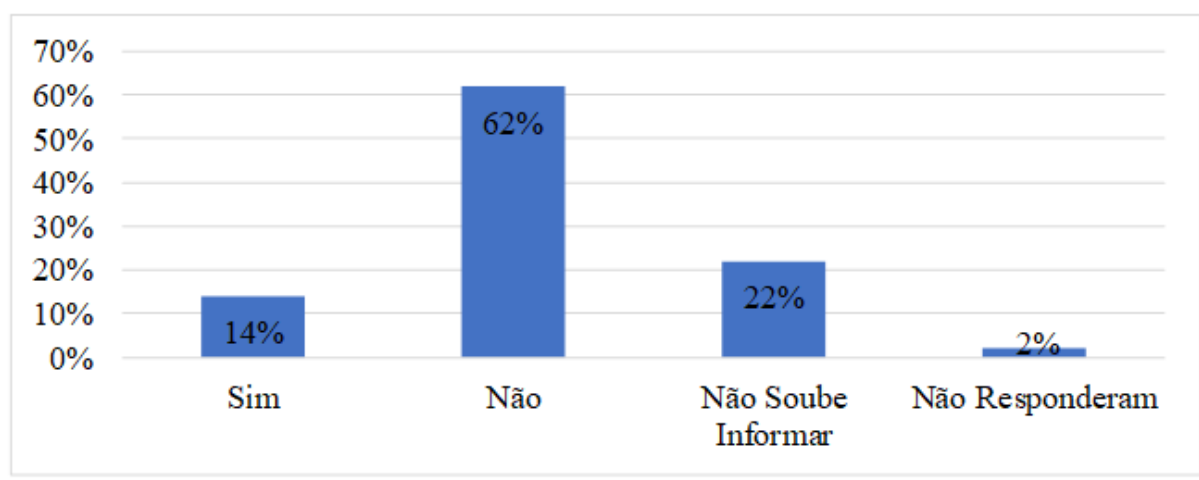

Fonte: Elaborado pela autora (2020)

A maioria dos respondentes informou que suas entidades não possuem indicadores para os processos e estratégias. (PAGLIUSO, 2010) sugere que para exercer a gestão dentro das organizações, é necessário possuir um conjunto de atividades, dentre elas, medir para lhes permitir gerenciar suas organizações.

Seis pesquisados deram exemplos de quais indicadores são utilizados em suas entidades, como indicadores de produtividade, qualidade, financeiro, representatividade, associatividade e de pessoas. De acordo com as respostas obtidas as práticas estão em desacordo com os autores, visto que a maioria das entidades sindicais não possui sequer seus processos mapeados e ou desenhados, muito menos, relacionados a indicadores.

i) Pergunta 9: A Entidade investe na capacitação de seus colaboradores?

Figura 9 - Resultados da Pergunta 9

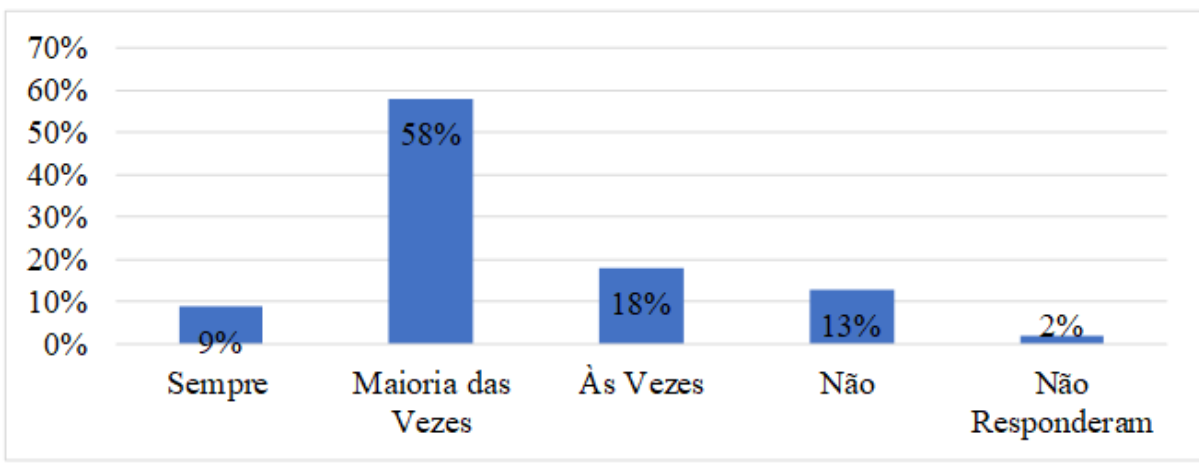

Fonte: Elaborado pela autora (2020) 
De acordo com o gráfico a maioria dos respondentes informou que suas entidades na maioria das vezes investem na capacitação de seus colaboradores atendendo o embasamento do Guia de Excelência do SEGS - Sistema de Excelência em Gestão Sindical. A gestão tem que estar voltada ao seu público interno, seus colaboradores. Já NBR ISO 9001:2015 no item 7.2 sugere que a organização selecione pessoas que possuam as respectivas competências necessárias para desempenhar suas funções dentro da organização para qual foi contratada e, quando for o caso, oferecer treinamentos para desenvolver essas competências, o que resultará em uma equipe qualificada com conhecimento necessário para execução eficaz das atividades.

j) Pergunta 10: Você implantaria em sua Entidade um Modelo de Gestão para a Qualidade? Justifique seu posicionamento.

Figura 10 - Resultados da Pergunta 10

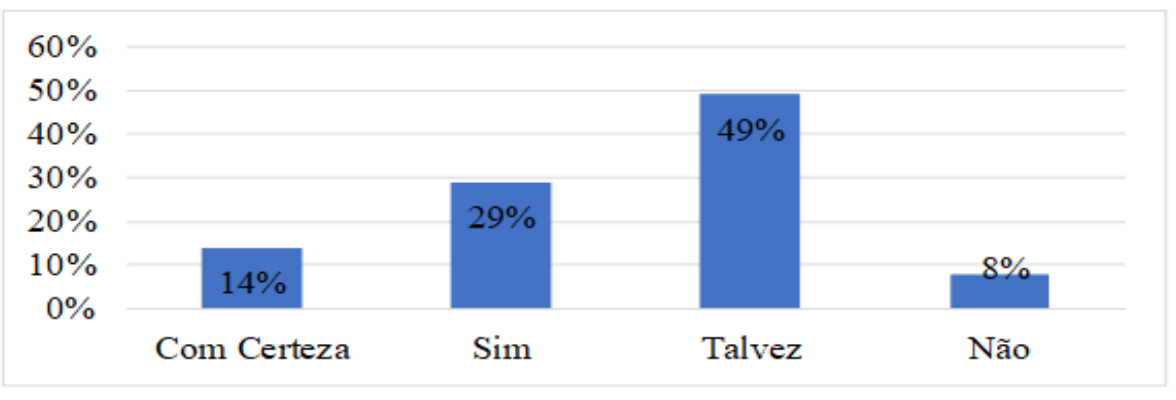

Fonte: Elaborado pela autora (2020)

De acordo com o gráfico grande parte dos respondentes informou que talvez implementaria um modelo de gestão. Dependeria de qual modelo e, se realmente traria um benefício e não burocracia ao sistema e, se houvesse, também, um retorno financeiro adequado.

(DEFEO, 2015) cita que bens e serviços de qualidade são sinônimos de resultados financeiros dentro das organizações. Os processos entregues sem falhas e de forma eficiente e eficaz influenciam totalmente no desempenho financeiro e que a falta de qualidade pode gerar custos extras. Esses custos podem acarretar em até $20 \%$ de retrabalho ocasionado pela má qualidade.

Outros optaram por não implementarem pelo fato ser muito burocrático e trabalhoso. De fato, de acordo com Juran (2017), para se alcançar a qualidade, deve-se primeiramente alcançar e atender os objetivos dos clientes de acordo com o perfil de cada um, independentemente de sua necessidade, e muitas das entidades pesquisadas não tem essa troca de informações com seus clientes. Maximiano (2011), enfatiza a necessidade das organizações de se aprimorar continuamente, e para isso, é necessário planejar, executar e agir, através de um ciclo que se 
repete gradativamente, o PDCA. Todas essas ações elencadas, são na maioria burocráticas e totalmente trabalhosa, mas essenciais para se obter a qualidade.

De acordo com Falconi (2014), um modelo de gestão da qualidade é um método eficaz para controlar, padronizar e medir os resultados, melhorar a performance da entidade, aumentar a produtividade, evitar o retrabalho e reduzir custos, sustentar uma gestão estratégica eficaz, tomar decisões mais próximo possível do acerto para que se consiga a satisfação do cliente. E por fim Maximiano (2011). Descreve o papel de um dirigente, ou da liderança, como responsável pelas tomadas de decisões, por estabelecer metas, escolher as diretrizes, delegar responsabilidades, ou seja, a liderança é responsável por planejar, organizar, comandar, coordenar e controlar. Portanto a decisão em se implantar um Modelo de Gestão para a Qualidade é da liderança, é de cima para baixo. Se o presidente optar, embora sua força de trabalho não coadune da mesma opinião, o que prevalece é a determinação do presidente.

A implementação, ou não, depende da perspectiva de futuro que cada líder tem para sua entidade sindical.

Considerando os resultados da pesquisa e as sugestões da literatura é possível sugerir que estas entidades sindicais realizem um levantamento das ações de gestão exercidas em seus sindicatos, com finalidade de se obter um grau de maturidade. Esse levantamento poderá ser realizado listando os processos macro e de apoio que contemplem as áreas sindicais como liderança, processo, pessoas, clientes, financeiro, infraestrutura e tecnologia. Essas ações tem que estarem desenhadas a ponto de todos na entidade terem acesso a esse mapeamento, independente se as ações estão sendo eficiente e eficazes, as mesmas devem ser desenhadas. A tabela 1, foi desenvolvida neste trabalho para propor uma pontuação a ser preenchida para ter uma visão sistêmica do grau de maturidade que a entidade se encontra. Nesta etapa não tem como objetivo a medição e tampouco, avaliação da eficiência e eficácia da prática, mas simplesmente um diagnóstico para auxiliar nas tomadas de decisão. Abaixo na tabela 2, segue orientações para se realizar o levantamento das ações para medir o grau de maturidade. 
Tabela 1: Pontuação para Mensuração da Gestão e Mapeamento de Ações de Gestão

\begin{tabular}{|c|c|c|c|c|c|c|c|c|c|c|c|c|c|c|}
\hline \multicolumn{6}{|c|}{ Tabela de Pontuação } & \multicolumn{9}{|c|}{ MAPA DE AÇÕES } \\
\hline \multirow[b]{2}{*}{ Esferas } & $0 \%$ & $30 \%$ & $60 \%$ & $80 \%$ & $100 \%$ & \multirow[b]{2}{*}{$\begin{array}{l}O \text { que } \\
\text { é feito }\end{array}$} & \multirow[b]{2}{*}{\begin{tabular}{|l|} 
Como \\
é feito
\end{tabular}} & \multirow[b]{2}{*}{$\begin{array}{c}\text { Quando } \\
\text { é feito }\end{array}$} & \multirow[b]{2}{*}{$\begin{array}{c}\text { Responsável } \\
\text { pela ação }\end{array}$} & \multirow[b]{2}{*}{$\begin{array}{l}\text { Quem tem } \\
\text { acesso as } \\
\text { informaçōes }\end{array}$} & \multirow[b]{2}{*}{ Indicador } & \multicolumn{2}{|c|}{ Medições } & \multirow[b]{2}{*}{$\begin{array}{l}\text { Programação } \\
\text { de Melhorias }\end{array}$} \\
\hline & $\begin{array}{c}\text { Não possui } \\
\text { nenhuma } \\
\text { ação }\end{array}$ & $\begin{array}{c}\text { Possui ação, } \\
\text { mas não está } \\
\text { mapeada }\end{array}$ & $\begin{array}{c}\text { Possui ação e } \\
\text { a mesma está } \\
\text { mapeada }\end{array}$ & $\begin{array}{c}\text { Possui a ação, } \\
\text { mapeamento e } \\
\text { controle }\end{array}$ & $\begin{array}{c}\text { Possui ação } \\
\text { mapeada, controle } \\
\text { e mediçẫo }\end{array}$ & & & & & & & & 2 & \\
\hline \multicolumn{15}{|c|}{ Ações Sindicais } \\
\hline \multicolumn{15}{|l|}{ Liderança } \\
\hline \multicolumn{15}{|l|}{ Processos } \\
\hline \multicolumn{15}{|l|}{ Pessoas } \\
\hline \multicolumn{15}{|l|}{ Clientes } \\
\hline \multicolumn{15}{|l|}{ Financeiro } \\
\hline $\begin{array}{l}\text { Infraestrutura } \\
\text { e Tecnologia }\end{array}$ & & & & & & & & & & & & & & \\
\hline
\end{tabular}

Fonte: Elaborado pela autora (2020)

Tabela 2: Orientações para Levantamento de Ações para Medir o Grau de Maturidade

\begin{tabular}{|c|c|}
\hline Esferas & Exemplos de Ações \\
\hline Ações Sindicais & $\begin{array}{l}\text { Ações realizadas pela entidade em prol da categoria representada, o que é feito: } \\
\text { Negociação coletiva, parcerias com os governos estadual e municipal, participações em } \\
\text { conselhos de representações federais, estaduais e municipais, federativos e confederativos. }\end{array}$ \\
\hline Liderança & $\begin{array}{l}\text { Ações de interações promovidas pela liderança da entidade, como: Assembleias, reuniões } \\
\text { de diretoria, congressos, feiras, etc... }\end{array}$ \\
\hline Processos & $\begin{array}{l}\text { Levantamento dos processos da entidade: Descrição dos processos, mapeamento, } \\
\text { melhorias, controle, tipos de documentos utilizados na entidade, escolha de fornecedores, } \\
\text { etc... }\end{array}$ \\
\hline Pessoas & $\begin{array}{l}\text { Como a entidade interage com seus funcionários: Como são definidos os cargos e funções, } \\
\text { se são realizados treinamentos e capacitação de seus colaboradores, se o desempenho é } \\
\text { medido, etc... }\end{array}$ \\
\hline Clientes & $\begin{array}{l}\text { Ações direcionadas somente aos clientes: Associatividade, atualização de cadastro, } \\
\text { convênios, identificação de necessidades dos clientes, forma de comunicação com seus } \\
\text { clientes, controle de qualidade dos produtos e serviços oferecidos aos clientes, etc... }\end{array}$ \\
\hline Financeiro & $\begin{array}{l}\text { Ações que são realizadas para prover sustentos financeiros e controle dos fundos, como: } \\
\text { Parcerias, convênios, ações que capta novos associados, controles financeiros (fluxo de } \\
\text { caixa, DRE, balancetes, balanço, previsão orçamentária), etc.. }\end{array}$ \\
\hline $\begin{array}{l}\text { Infraestrutura e } \\
\text { Tecnologia }\end{array}$ & $\begin{array}{l}\text { Levantamento de necessidade da demanda } \mathrm{x} \text { oferta, exemplos: Se há espaço físico } \\
\text { adequado para atendimento dos clientes, se os colaboradores possuem infraestrutura e } \\
\text { equipamentos necessários para desempenhar suas funções, etc... }\end{array}$ \\
\hline
\end{tabular}

Fonte: Elaborado pela autora (2020)

\section{Conclusão}

A literatura delineada através de pesquisa bibliométrica trouxe a este estudo respaldo que permite a liderança destas entidades sindicais obter a percepção de gestão da qualidade. Vários autores alicerçaram que as organizações precisam praticar os conceitos da qualidade e que bens e serviços de qualidade são sinônimos de resultados financeiros sustentáveis dentro das organizações. Para ser possível implantar um modelo de gestão sustentável é necessário implementar um modelo de gestão da qualidade, o qual possibilitará padronizar e medir os resultados, melhorar a performance da entidade, aumentar a produtividade, evitar o retrabalho 
e reduzir custos, sustentar uma gestão estratégica eficaz, tomar decisões mais próximo possível do acerto para que se consiga a satisfação do cliente e com isto a captação e a fidelização deste.

\section{REFERÊNCIAS}

ASSOCIAÇÃO BRASILEIRA DE NORMAS TÉCNICAS. ABNT NBR ISO 9001:2015: Sistemas de Gestão da Qualidade - Requisitos, p. 7, 2015.

CAMPOS, Vicente Falconi. TQC - Controle da Qualidade Total no Estilo Japonês. Editora Falconi, p. 26, 2014.

CARVALHO, Augusto Cesar Leite de. Direito do Trabalho - Curso e Discurso. Editora LTR, p. 27, 2011.

CUNHA, Lomanto et al. Modernização Sindical no Brasil e a Luta pela Sobrevivência das Classes Representativas em Pleno Século XXI. Revista Jurídica, Paripiranga, Bahia, Brasil, p. 8, v. 1, n. 2, jul./dez. 2018.

DEFEO, Joseph. Fundamentos da Qualidade. Editora Bookman, p. 19, 2015.

FEIGENBAUM, Armand V. Controle da Qualidade Total. Editora Makron Books, v. 3, p. 93-100, 1994.

GRAY, David E. Pesquisa no Mundo Real. Editora Artmed, p. 20-108, 2012.

JURAN, J. M. A Qualidade Desde o Projeto. Editora Cengage Learning, p. 10, 2017.

Lei $\mathrm{N}^{\mathrm{o}} 13.467$ (13 de julho de 2017). Disponível em:

http://www.planalto.gov.br/ccivil_03/_ato2015-2018/2017/lei/113467.htm. Fonte: Planalto Presidência da República. Acesso em: 22/03/1019.

MAXIMIANO, Antônio César Amaru. Introdução à Administração - $5^{\mathrm{a}}$ Ed. Editora Atlas, p. 51-73, 2000.

MAXIMIANO, Antônio César Amaru. Introdução à Administração - $8^{\mathrm{a}}$ Ed. Editora Atlas, p. 21-98, 2011.

Medida Provisória No 873 (11 de junho de 2019). Disponível em:

http://www.planalto.gov.br/ccivil_03/_ato2019-2022/2019/Mpv/mpv873.htm. Fonte: Planalto Presidência da República. Acesso em: 22/03/1019.

MOMBACH, Odair José et al. Artigo: Proposta de um Modelo de Gestão pela Qualidade para um Abatedouro/Frigorifico de Suínos. Revista Agrariam, p. 295-299, 2011.

NASCIMENTO, Amauri Mascaro. Direito Sindical. Editora Saraiva, p. 48, 1989. 
OLIVEIRA, Fernando Alves de. S. O. S. Sindical pt - O que os Contribuintes dos Sindicatos e a Sociedade Precisam saber sobre o Sindicalismo Brasileiro e Suas Graves Contradições. Editora LTR, p. 13, 2009.

PAGLIUSO, Antônio Tadeu. Gestão Organizacional. Editora Saraiva, p. 56-80, 2010.

PAGLIUSO, Antônio Tadeu. MEG - Modelo de Excelência da Gestão - $21^{\text {a }}$ Edição. Fundação Nacional da Qualidade, p. 17, 2016. 